\title{
Enhancing the Attraction Efficiency of GF-120 for the Mediterranean Fruit Fly, Ceratitis capitata (Wied.) by Adding some Ammonium Compounds El-Metwally, M. M.* \\ Plant Protection Research Institute, ARC. Dokki, Giza, Egypt \\ *Corresponding author; e-mail: mhran552@yahoo.com
}

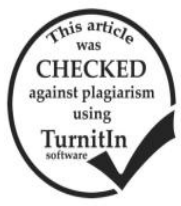

\section{ABSTRACT}

The present investigation aims to evaluate efficacy of adding some ammonium compounds to Conserve (GF-120) when used at different concentrations, $(0.5,1.0,2.0$ and 3.0\% (wt./vol.) on attraction of the Mediterranean fruit fly (MFF). These compounds included; ammonium acetate (AA), Di-ammonium phosphate (DAP) and ammonium carbonate (AC). The relationship between attraction flies and $\mathrm{pH}$ values of the bait solution was also investigated. Field experiments were carried out at Dakahlia Governorate during October 2017 at Guava and Citrus orchards. The obtained results indicated a positive relationship between concentrations of all tested ammonium compounds and the number of attracted flies to GF-120 concentrations. Also, there were positive responses between $\mathrm{pH}$ values and the attracted flies (females, males or total). Females responded significantly more than males to $\mathrm{pH}$ values. Additions of $3 \%$ DAP or $2-3 \%$ AC to GF-120 enhanced its attraction to Ceratitis capitata, potentially increasing the bait's efficacy in applying integrated pest management programs for C. capitata.

Keywords: GF-120, Ceratitis capitata, ammonium compounds, PH

\section{INTRODUCTION}

Tephritid fruit flies are serious insect pests to many fruits and vegetables (Khattak et al., 1997). Fruit flies (Diptera: Tephritidae) include approximately 4,500 species distributed all over the world (White and Elson-Harris, 1992; Tan and Nishida, 1998). Adult tephritid fruit fly females require protein sources for egg production. Ammonia and its derivatives serve as volatile cues to locate protein-rich food (Piñero et al., 2017).

The female-targeted system normally consists of traps baited with a liquid solution consists of protein and fermenting sugar (Epsky et al., 1999). The protein hydrolyzate preparations (food attractants) were previously used as a bait in McPhail traps (Steyskal, 1977), and they captured a large number of both males and females of MFF (Saafan 2005). Food-baited traps are important component of fruit fly management programs that are neither sex- nor species specific (Epsky et al., 2014).

GF-120 ${ }^{\mathrm{TM}}$ (Naturalyte, Dow Chemical) is a product that is registered for use in tree fruit production and uses an 'attract and kill' approach. It is sugar-based bait containing a low concentration of spinosad $(0.02 \% \mathrm{w} / \mathrm{w})$. Benefits of GF120 include the very low dose need (1.5 L/2.33 Fedan) and that it degradable in a short time causing no residues on the crop (OEHHA 2016). GF-120 NF (Dow AgroSciences, Indianapolis, IN) (GF-120) has been the most frequently tested bait against subtropical, tropical, and temperate fruit flies (e.g. Vargas et al., 2002; Prokopy et al., 2003 and Barry \& Polavarapu, 2004). Field applications of GF-120 showed no adverse effect to honey bees (Rendon et al. 2000) with minimal or no influence to natural enemies (Burns et al. 2001; Michaud 2003).

GF-120 is a modified, more concentrated and marketed version of Solbait originally developed for controlling Anastrepha and Ceratitis flies (Burns et al., 2001 and Moreno \& Mangan, 2003). The frequent testing of this bait is due to its effectiveness against representative tephritids, ease of use, low spray doses needed, and its safety to the environment. GF-120 contains $0.02 \%$ spinosad (wt/vol), an insecticide derived from fermentation of the bacterium Saccharopolyspora spinosa Mertz and Yao that has a high safety profile (Dow AgroSciences 2006) when mixed with $1 \%$ ammonium acetate as an attractant (Thomas \& Mangan, 2005). Bait sprays using GF-120 became the primary tool for area-wide control and suppression of tephritid fruit flies in the Hawaiian Islands (Vargas et al., 2008).

Researches conducted by (Barry \& Polavarapu 2004; Yee \& Chapman 2005; Yee 2006; Pelz-Stelinski et al. 2006) indicated that GF-120 is not or slightly attractive to Rhagoletis flies, therefore enhancing the attraction is needed. Since ammonia is associated with protein-rich foods, the logical choice of materials that could upgrade attractive are ammonia producer compounds (Hodson 1948).

A Significant effect of adding AA to GF-120, regardless of the amount added, for Bactrocera cucurbitae (Coquillet) and Bactrocera dorsalis (Hendel) was recorded, in case of $C$. capitata a significant positive relationship between relative amounts of AA in the bait and the numbers of responded females was noted (Piñero et al. 2011).

The $\mathrm{pH}$ value in the mixture plays an important role in attracting fruit flies. Fewer fruit flies are attracted to the mixture as the $\mathrm{pH}$ becomes more acidic. Hydrolyzed protein is not effective over time as the $\mathrm{pH}$ drops from its initial state of 8.5 (IAEA, 2003). The addition of $1-10 \%$ borax to $10 \%$ NuLure solution increased its $\mathrm{pH}$, which corresponded directly with an increase in a number of $C$. capitata female trapped in field trials (Heath et al., 1994).

The $\mathrm{pH}$ also may affect amounts of consumed baits; however, there was a significant difference in attractiveness of B. cucurbitae when the $\mathrm{PH}$ of Buminal solutions ranged between 3 and 6 (Hu et al., 1999 and Rousse et al., 2005).

The objectives of the present study were to determine attractively of GF-120 to the Mediterranean fruit fly either alone or when ammonium acetate, di-ammonium phosphate or ammonium carbonate were added at different concentrations, moreover to determine the relationship between the number of attracted flies and $\mathrm{pH}$ value of the bait solution.

\section{MATERIALS AND METHODS}

The present experiments were carried out in guava (Psidium guajava L.) and navel orange (Citrus sinensis L.) orchards located in the experimental farm of Mansoura University, Mansoura district $\left(31.03^{\circ} \mathrm{N}, 31.04^{\circ} \mathrm{E}\right)$. The area was about (seven feddans) cultivated with guava and about (eight feddans) cultivated with navel orange. The 
experiments were carried out during the period from the $9^{\text {th }}$ till $20^{\text {th }}$ of October 2017 in guava and from the $20^{\text {th }}$ till $31^{\text {th }}$ of October 2017 in navel orange orchards.

1.Used chemicals:

GF-120 (Conserve $0.024 \%$ CB from Dow Agrosciences, England) in addition to Ammonium compounds. Three local ammonium compounds from ElNaser for Drugs and Chemicals Co., were selected in the present study; Ammonium acetate [CH3COONH4], Diammonium phosphate [(NH4)2 HPO4] and Ammonium carbonate [(NH4)2 CO3.

GF-120 was preparing at the concentration of 5\% (vol./vol.) and used alone or mixed with ammonium compounds. Each ammonium compound was added to GF-120 with the four concentrations of $0.5,1.0,2.0$ and $3.0 \%$ (wt./vol.).

\section{Field experiments:}

The modified Nadel traps (described by Hanafy et $a l ., 2001$ ) were used in this experiment. Five traps (as replicates) for each treatment were distributed randomly where the distance between every two adjacent traps was about 20 meters to avoid the interaction among lures. All traps were hanged at a height of 2 meters above ground in a shaded place of trees. Traps were inspected every 2 days along a period of 12 days of hanging without renewal of the bait solution. Captured flies were collected, counted, inspected, (as females \& males) and number of attracted flies per trap per day (FTD) were calculated.

All above mentioned treatments were carried out in a guava orchard and repeated again in navel orange orchard.

\section{Determination of $\mathbf{p H}$ value:}

$50 \mathrm{ml}$ of each tested treatments was transferred to Laboratory. $\mathrm{pH}$ s value of these samples were measured by Jenway $3510 \mathrm{pH}$ meter.

\section{Statistical analysis:}

Data collected in this experiments were analyzed using analysis of variance (ANOVA) followed by Least Significant Difference (LSD). The probability of 0.05 or less was considered significant. All statistical analysis was done with (CosStat, 1990), in addition to the regression analysis was done to the obtained data.

\section{RESULTS}

Data represented in Table (1) showed that GF$120+3.0 \%$ DAP (mean FTD was 15.81 ) followed by GF$120+2.0 \%$ DAP $(\mathrm{FTD}=13.77)$ and GF-120+3.0\% AC $(\mathrm{FTD}=11.96)$ were the highest effective treatments in attracting MFF flies in guava orchard with significant differences between them. On the contrary, the lowest effective treatments were those of GF-120+1.0\% AA (FTD $=1.98)$ and $\mathrm{GF}-120$ alone $(\mathrm{FTD}=2.81)$ with no significant difference between them.

On another hand, Table (1) showed that GF-120 alone and GF-120+AA3.0\% exhibited approximately the same trend attraction allover the 12 days of study. When adding $0.5,1.0 \& 2.0 \% \mathrm{AA}$ the ability to attraction started to decrease after 6 days of hanging traps. When adding all concentrations of di-ammonium phosphate or ammonium carbonate to GF-120, the ability to attraction decreased after 2 days. Although the decreasing of attraction in the cases of DAP 2.0 or AC3.0\% after 2 days, it was the significantly highest effective treatments at the second half of study's period (from 6 to 12 days).

So, it could be noticed that adding DAP to GF-120 at ratios of $3.0 \& 2.0 \%$ and $\mathrm{AC}$ at a ratio of $3.0 \%$ increased its attraction by $5.63,4.90$ and 4.26 folds, respectively in comparison with GF-120 alone.

Table 1. Mean number of MFF flies per trap per day (FTD) attracted to GF-120 either alone or added with ammonium acetate, di-ammonium phosphate or ammonium carbonate at different concentrations within 12 days in guava orchard at Dakahlia governorate.

\begin{tabular}{|c|c|c|c|c|c|c|c|}
\hline \multirow{2}{*}{ Treatment } & \multicolumn{6}{|c|}{ FTD \pm SD after (days) } & \multirow{2}{*}{ Mean } \\
\hline & 2 days & 4 days & 6 days & 8 days & 10 days & 12 days & \\
\hline GF-120 & $2.13 \pm 0.75$ & $2.75 \pm 0.65$ & $3.00 \pm 0.71$ & $3.00 \pm 0.91$ & $3.13 \pm 0.48$ & $2.88 \pm 0.48$ & $2.81 \pm 0.49$ \\
\hline GF- $120+0.5 \%$ AA & $3.25 \pm 0.87$ & $4.25 \pm 0.65$ & $4.88 \pm 0.95$ & $3.88 \pm 1.11$ & $1.63 \pm 1.11$ & $0.75 \pm 0.29$ & $3.10 \pm 0.72$ \\
\hline GF- $120+1.0 \%$ AA & $2.00 \pm 0.41$ & $2.25 \pm 0.50$ & $3.88 \pm 1.44$ & $2.50 \pm 0.71$ & $0.88 \pm 0.25$ & $0.38 \pm 0.47$ & $1.98 \pm 0.51$ \\
\hline GF- $120+2.0 \% \mathrm{AA}$ & $4.63 \pm 1.18$ & $5.13 \pm 0.63$ & $6.00 \pm 2.41$ & $5.38 \pm 0.48$ & $3.00 \pm 1.00$ & $1.38 \pm 0.75$ & $4.25 \pm 0.79$ \\
\hline GF-120+3.0\%AA & $6.00 \pm 0.58$ & $5.25 \pm 1.32$ & $4.38 \pm 0.48$ & $5.00 \pm 0.71$ & $5.88 \pm 1.11$ & $5.13 \pm 0.85$ & $5.27 \pm 0.65$ \\
\hline GF $-120+0.5 \% \mathrm{DAP}$ & $5.25 \pm 1.75$ & $4.50 \pm 0.41$ & $4.00 \pm 0.82$ & $2.13 \pm 0.63$ & $0.88 \pm 0.48$ & $1.38 \pm 0.25$ & $3.02 \pm 0.49$ \\
\hline GF $-120+1.0 \%$ DAP & $20.13 \pm 3.54$ & $10.50 \pm 2.04$ & $5.00 \pm 1.29$ & $3.75 \pm 1.19$ & $1.63 \pm 1.11$ & $1.38 \pm 0.48$ & $7.06 \pm 1.16$ \\
\hline GF $-120+2.0 \% \mathrm{DAP}$ & $38.38 \pm 1.95$ & $16.25 \pm 1.03$ & $6.38 \pm 0.65$ & $8.13 \pm 0.74$ & $7.00 \pm 1.12$ & $6.50 \pm 0.79$ & $13.77 \pm 0.74$ \\
\hline GF $-120+3.0 \%$ DAP & $53.38 \pm 2.36$ & $19.75 \pm 1.19$ & $6.50 \pm 1.22$ & $6.75 \pm 0.50$ & $4.13 \pm 0.63$ & $4.38 \pm 1.60$ & $15.81 \pm 0.62$ \\
\hline $\mathrm{GF}-120+0.5 \% \mathrm{AC}$ & $28.63 \pm 2.63$ & $16.13 \pm 0.95$ & $5.25 \pm 1.44$ & $3.13 \pm 1.55$ & $1.25 \pm 0.50$ & $1.00 \pm 0.91$ & $9.23 \pm 0.74$ \\
\hline GF- $120+1.0 \% A C$ & $22.38 \pm 1.44$ & $15.00 \pm 0.71$ & $5.00 \pm 0.00$ & $1.63 \pm 0.75$ & $1.38 \pm 0.48$ & $1.75 \pm 0.87$ & $7.85 \pm 0.44$ \\
\hline $\mathrm{GF}-120+2.0 \% \mathrm{AC}$ & $16.63 \pm 0.63$ & $9.75 \pm 0.65$ & $6.25 \pm 0.65$ & $3.75 \pm 0.29$ & $2.50 \pm 1.22$ & $2.88 \pm 0.85$ & $6.96 \pm 0.25$ \\
\hline GF- $120+3.0 \%$ AC & $21.63 \pm 2.56$ & $14.88 \pm 0.63$ & $11.13 \pm 1.11$ & $9.38 \pm 2.25$ & $7.00 \pm 0.91$ & $7.75 \pm 1.71$ & $11.96 \pm 0.97$ \\
\hline $\operatorname{LSD}(p=5 \%)$ & 2.70 & 1.41 & 1.67 & 1.49 & 1.26 & 1.30 & 1.02 \\
\hline $\mathrm{F}$ & 283.33 & 151.95 & 11.68 & 20.33 & 25.87 & 26.81 & 156.09 \\
\hline $\mathrm{P}$ & $<.001$ & $<0.001$ & $<0.001$ & $<0.001$ & $<0.001$ & $<0.001$ & $<0.001$ \\
\hline
\end{tabular}

In case of navel orange, the highest effect of all treatments was recorded after 6 days of hanging traps except those of GF-120+0.5\% AC (after 4 days) and GF- $120+3.0 \%$ AC (after 8 days). After that, all of the tested treatments decreased sharply till the end (Table, 2). The highest effective treatment in attracting MFF flies in navel orange was noticed in of GF-120+2.0\% AC (mean FTD was 6.67) followed by GF-120+3.0\% DAP (FTD $=5.56)$ with significant differences between them (Table, 2). On the contrary, the lowest effective treatments were those of GF120 alone $(\mathrm{FTD}=1.58)$ and GF-120+AA1.0\% $(\mathrm{FTD}=$ 1.60) with no significant difference between them. So, adding ammonium carbonate to GF-120 at a ratio of $2.0 \%$ increased its attraction by 4.22 folds; while adding diammonium phosphate at a ratio of $3.0 \%$ increased attraction of GF-120 by 3.52 folds in comparison with GF-120 alone. 
Table 2. Mean number of MFF flies per trap per day (FTD) attracted to GF-120 either alone or added with ammonium acetate, di-ammonium phosphate or ammonium carbonate at different concentrations within 12 days in navel orange orchard at Dakahlia governorate.

\begin{tabular}{|c|c|c|c|c|c|c|c|}
\hline \multirow{2}{*}{ Treatment } & \multicolumn{6}{|c|}{ FTD \pm SD after (days) } & \multirow[b]{2}{*}{ Mean } \\
\hline & 2 days & 4 days & 6 days & 8 days & 10 days & 12 days & \\
\hline GF-120 & $0.85 \pm 0.25$ & $1.28 \pm 0.38$ & $4.13 \pm 0.48$ & $0.88 \pm 0.25$ & $0.88 \pm 0.48$ & $1.50 \pm 0.41$ & $1.58 \pm 0.12$ \\
\hline GF- $120+0.5 \%$ AA & $1.10 \pm 0.26$ & $1.65 \pm 0.39$ & $7.00 \pm 1.41$ & $2.13 \pm 1.11$ & $1.00 \pm 0.71$ & $1.00 \pm 0.41$ & $2.31 \pm 0.63$ \\
\hline GF- $120+1.0 \% \mathrm{AA}$ & $1.15 \pm 0.19$ & $1.73 \pm 0.29$ & $3.88 \pm 1.55$ & $1.38 \pm 0.48$ & $0.88 \pm 1.18$ & $0.63 \pm 0.49$ & $1.60 \pm 0.31$ \\
\hline $\mathrm{GF}-120+2.0 \% \mathrm{AA}$ & $1.55 \pm 0.60$ & $2.33 \pm 0.90$ & $12.50 \pm 0.71$ & $3.88 \pm 1.44$ & $0.88 \pm 0.85$ & $0.50 \pm 0.71$ & $3.60 \pm 0.28$ \\
\hline GF- $120+3.0 \% \mathrm{AA}$ & $1.25 \pm 0.38$ & $1.88 \pm 0.57$ & $6.88 \pm 1.65$ & $1.88 \pm 1.79$ & $1.75 \pm 0.86$ & $0.88 \pm 0.48$ & $2.42 \pm 0.47$ \\
\hline GF- $120+0.5 \%$ DAP & $1.35 \pm 0.25$ & $2.03 \pm 0.38$ & $6.88 \pm 0.48$ & $1.50 \pm 2.67$ & $1.13 \pm 0.63$ & $1.00 \pm 1.08$ & $2.31 \pm 0.88$ \\
\hline GF- $120+1.0 \%$ DAP & $4.30 \pm 0.58$ & $6.45 \pm 0.87$ & $13.13 \pm 2.93$ & $3.63 \pm 2.01$ & $1.63 \pm 1.10$ & $0.75 \pm 0.64$ & $4.98 \pm 0.94$ \\
\hline GF- $120+2.0 \%$ DAP & $4.80 \pm 0.49$ & $7.20 \pm 0.73$ & $9.00 \pm 1.47$ & $1.38 \pm 1.70$ & $0.88 \pm 0.75$ & $0.38 \pm 0.47$ & $3.94 \pm 0.81$ \\
\hline GF- $120+3.0 \%$ DAP & $5.15 \pm 0.44$ & $7.73 \pm 0.67$ & $12.38 \pm 2.17$ & $2.00 \pm 1.58$ & $5.25 \pm 0.65$ & $0.88 \pm 1.03$ & $5.56 \pm 0.57$ \\
\hline $\mathrm{GF}-120+0.5 \% \mathrm{AC}$ & $4.65 \pm 0.79$ & $6.98 \pm 1.18$ & $5.13 \pm 0.85$ & $1.50 \pm 1.22$ & $1.88 \pm 0.63$ & $0.63 \pm 0.25$ & $3.46 \pm 0.58$ \\
\hline $\mathrm{GF}-120+1.0 \% \mathrm{AC}$ & $3.35 \pm 0.50$ & $5.03 \pm 0.75$ & $16.13 \pm 1.49$ & $1.25 \pm 1.55$ & $1.13 \pm 1.03$ & $0.50 \pm 0.00$ & $4.56 \pm 0.81$ \\
\hline GF- $120+2.0 \% \mathrm{AC}$ & $1.25 \pm 0.25$ & $1.88 \pm 0.38$ & $22.63 \pm 3.09$ & $8.75 \pm 2.60$ & $4.25 \pm 0.95$ & $1.25 \pm 0.86$ & $6.67 \pm 1.00$ \\
\hline GF- $120+3.0 \%$ AC & $2.25 \pm 0.68$ & $3.38 \pm 1.02$ & $1.63 \pm 1.03$ & $16.63 \pm 1.25$ & $3.63 \pm 1.31$ & $1.25 \pm 0.50$ & $4.79 \pm 0.56$ \\
\hline $\mathrm{LSD}_{\mathrm{p}=5 \%}$ & 0.67 & 1.01 & 2.41 & 2.42 & 1.27 & 0.90 & 0.94 \\
\hline $\mathrm{F}$ & 49.01 & 49.01 & 47.64 & 23.74 & 10.93 & 1.14 & 23.07 \\
\hline $\mathrm{P}$ & $<0.001$ & $<0.001$ & $<0.001$ & $<0.001$ & $<0.001$ & $<0.001$ & $<0.001$ \\
\hline
\end{tabular}

As illustrated from Fig. (1), it can be concluded that adding di-ammonium phosphate or ammonium carbonate to GF-120 resulted in higher efficacy in attracting MFF adult flies; where the general means of FTD for all tested concentrations of both were 9.92 and 9.00 in guava orchard, which were 4.20 and 4.87 case of navel orange. On the contrary, when adding ammonium acetate to GF-120 it showed a relatively low efficiency in attracting this pest.

The general mean of FTD for all concentrations of ammonium acetate reached 3.65 and 2.48 in guava and navel orange orchards, respectively. With respect to GF-120 alone, the general mean of FTD was 2.81 and 1.58 in guava and navel orange orchards.

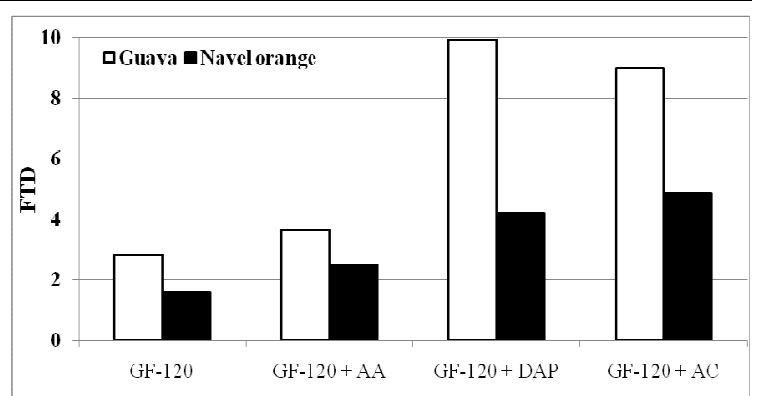

Fig. 1. The general mean of FTD of MFF all over 12 days by GF-120 alone or with adding ammonium compounds (at all concentrations) in guava and navel orange orchards.
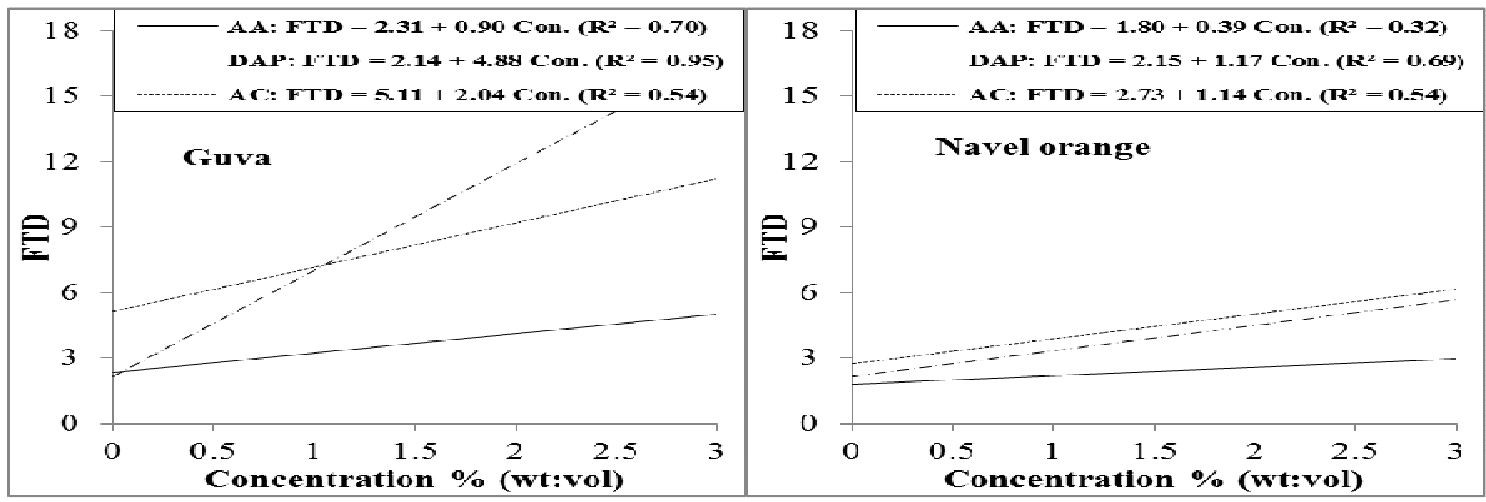

Fig. 2. The relationship between concentrations of ammonium compounds added to GF-120 and its efficiency in attracting MFF flies under field conditions of guava and navel orange orchards.

Data illustrated in Fig. (2) show the relationship between concentration of ammonium compounds added to GF-120 and its efficiency in attracting MFF flies. There was positive relationship between concentrations of all ammonium compounds and the attraction of GF120. Di-ammonium phosphate exhibited the highest response to the increase of its concentration. Each $1 \%$ increase of di-ammonium phosphate, ammonium carbonate and ammonium acetate increased the FTD value of GF-120 in guava orchard by 4.88, 2.04 and
0.90, respectively; while, in navel orange orchards, these FTDs reached 1.17, 1.14 and 0.39 , respectively.

The obtained data showed that all of the tested compounds caused increasing number attracted females than males (Fig., 3). In guava orchard, the highest sex ratio (females: male) was recorded with GF-120+0.5\% DAP ( 2.45 females/ one male) followed by the GF$120+0.5 \%$ AA (2.10) and GF-120+3.0\% AC \% (2.05). On the contrary, the lowest sex ratio was recorded with GF-120 alone (1.08 females/one male) followed by GF$120+1.0 \%$ AA (1.33) and GF-120+3.0\% AA (1.38). 


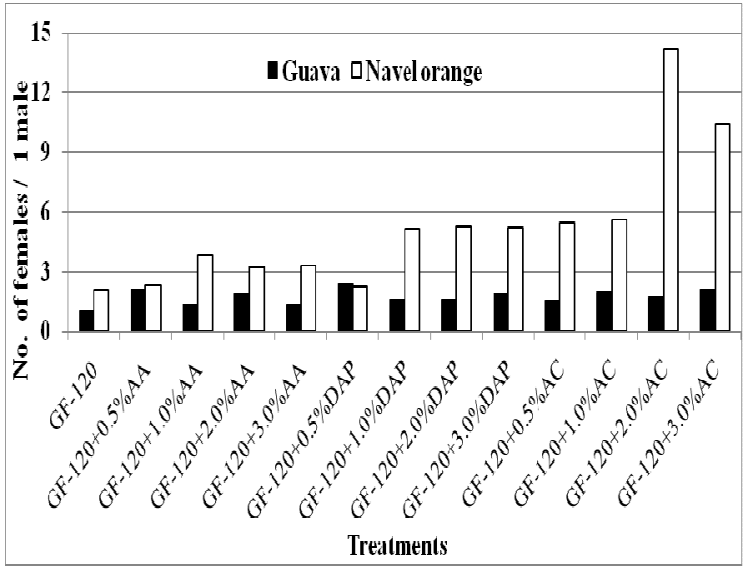

Fig. 3. Sex ratio (as No. of females/ 1male) of attracted MFF flies to GF-120 either alone or added with different concentrations of ammonium acetate, di-ammonium phosphate and ammonium carbonate in guava and navel orange orchards.

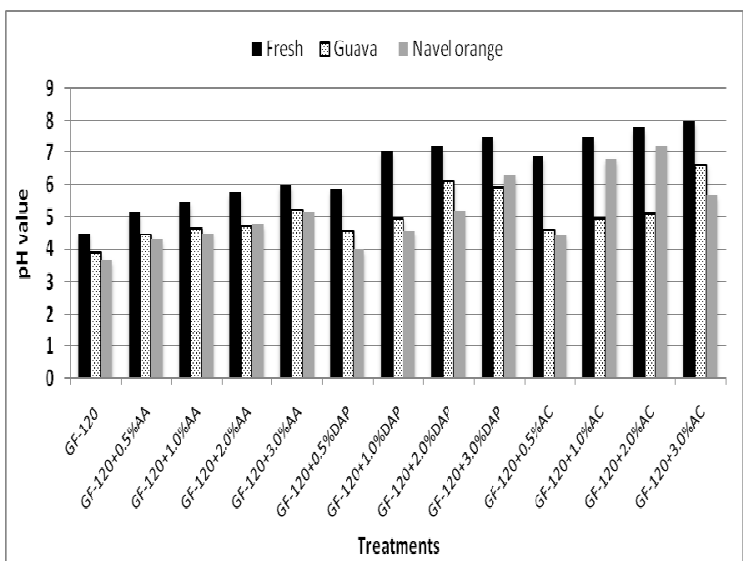

Fig. 4. Effect of added ammonium compounds to GF120 on $\mathrm{PH}$ value on fresh and old solutions in guava and navel orange orchards.

With respect to navel orange orchard, GF- $120+2.0 \%$ $\mathrm{AC}$ and GF-120 $+3.0 \%$ AC exhibited highest sex ratio; where, these treatments attracted induced sex ratio of 14.16 and 10.43 (Fig., 3). On the contrary, GF-120 alone, GF$120+0.5 \%$ DAP and GF- $120+0.5 \%$ AA exhibited the sex ratio $(2.04,2.25$ and 2.36$)$.

Moreover, it can be noticed from Fig. (3) that sex ratio was obviously higher in navel orange that in guava orchards at all of the tested treatment.

Relationship between added ammonium compounds to GF-120 and PH values is illustrated in Fig. (4). The $\mathrm{pH}$ of freshly prepared bait (at the beginning) and at the end (old) of each experiment (12 days) were determine. $\mathrm{PH}$ value in freshly prepared baits ranged between 4.51 and 8.01 recorded by GF-120 and GF- $120+3.0 \%$ AC, respectively Fig.( 4). While these values in old baits ranged between 3.92 noticed with GF-120 and 6.62 with GF-120+3.0\% AC in guava orchard. In case of $\mathrm{PH}$ values in old baits in navel orange orchard its, ranged between 3.69 with GF-120 and 7.21 with GF-120+2.0\%AC Fig.( 4).

The relationship between $\mathrm{pH}$ values and FTDs among all of the tested treatments is illustrated in Fig. (5). There were positive responses between $\mathrm{pH}$ value and the attracted flies (females, males or total). Females were more significantly responded to $\mathrm{pH}$ value than males in guava and navel orange orchards. The mathematical relationships revealed that each an increase in $\mathrm{pH}$ by a value of one in fresh and old solutions induced an increase in the FTDs (as total) by 3.17 and 4.95 in guava orchard; while, in navel orange orchard, these FTDs reached 1.27 and 1.20, respectively.

\section{DISCUSSION}

The present study indicated that the addition of DAP or AC to GF-120 maximized the attraction of MFF. On the contrary, adding ammonium acetate to GF-120 showed a relatively low efficiency in attracting this pest. Piñero et al., 2015 mentioned that enhanced the attraction of protein baits to $C$. capitata by adding AA, which more important for females than for males and hence potentially increased the bait's efficacy for fruit fly monitoring and control. Our finding are in agreement with Yee (2007), who mentioned that $\mathrm{GF}-120+10 \% \mathrm{AC}$ was more attractive to apple maggot fly than GF-120 $+10 \%$ AA, proposing that, AC released more ammonia than AA. Sticky yellow panel traps baited with GF-120 + 10\% AC attracted more apple maggot flies than those baited with GF- $120+10 \%$ AA or GF-120 alone in the field. Fly attraction and feeding were greater for GF$120+10 \%$ or $2.5 \%$ AC or AA than GF-120 alone on apple leaves (Yee, 2007). Duration of cherry fruit fly feeding on GF-120 bait were enhanced by adding 5\% AA reaching 73.4 $\pm 21.0 \mathrm{~s}$ compared with $6.8 \pm 5.7 \mathrm{~s}$ using standard GF-120, fly visits to GF-120 were enhanced with 5\% AA which lasted an average of $337.6 \pm 72.6 \mathrm{~s}$, compared with $50.3 \pm$ $36.4 \mathrm{~s}$ for standard GF-120 in a field.(Pelz-telinski et al. 2006).

Among $\mathrm{pH}$ values of 4.5, 6.5 and 8.5 for protein bait and borax, the highest numbers of $C$. capitata attracted to McPhail traps was recorded at $\mathrm{pH}$ 8.5. (Paiva and Parra 2013). Amounts consumed may be affected by the baits $\mathrm{pH}$. $\mathrm{Hu}$ et al. 1999 when tested sucrose bait at different PH values (3.0-10), found that $\mathrm{PH} 6.4$ stimulate feeding response of apple maggot fly.

Bait protein $\mathrm{pH}$, may strongly affect trap efficacy (Epsky et al. 1993). The chemical composition of the bait may change by dead flies and modify its attraction, while living flies might emit attractive or repulsive volatiles (Rousse et al., 2005). Heath et al. (1994) showed that the $\mathrm{pH}$ of a NuLure $+1.0 \%$ borax solution could be considerably increased after $7 \mathrm{~d}$ of field use.

The increase in the sex ratios of all treatments in navel orange in comparison with guava orchards may be attributed to that guava fruits are more attractive for females to deposit their eggs when compared with navel orange fruits or may be due to the fact that the evaluation in navel orange was carried out at the beginning of crop maturity where fruit are less suitable for egg deposit and females could be more attracted to food sources, while in guava fruit were full rapid , many fruit fallen were and most flies (male and or females) are newly emergence and therefore flies attracted to food sources than egg deposit.

Application of these results for partial bait sprays with GF-120 would require further field experiments. In conclusion, overall results indicate the attraction of GF-120 to $C$. capitata can be maximize with adding DAP or AC. 


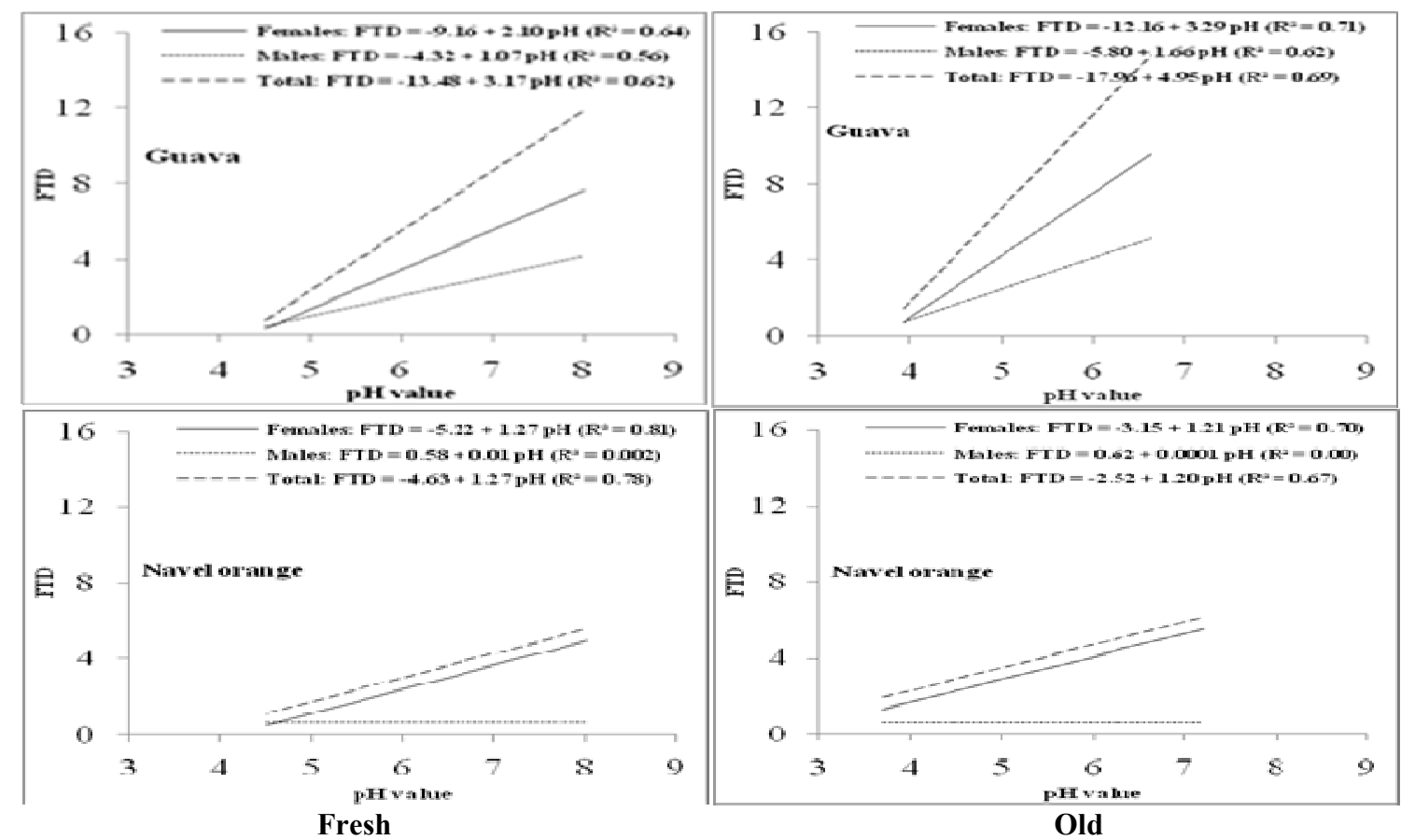

Fig. 5. The relationship between $\mathrm{pH}$ value (in fresh and old solutions) and FTDs among all of the tested treatments in guava and navel orange orchards.

\section{ACKNOWLEDGMENTS}

The author thanks, Dr. Nabil M. Ghanim and Dr. Reda Abd Elazim ElSharkawy (Plant Protection Research Institute, Agricultural Research Center, Ministry of Agriculture) for their assistance during conducting this work.

\section{REFERENCES}

Barry, J. D. and Polavarapu, S. (2004): Feeding activity and attraction of blueberry maggot (Diptera: Tephritidae) to protein baits, ammonium acetate, and sucrose. J. Econ. Entomol., 97: 1269 -1277.

Burns, R.E.; Harris, D.L.; Moreno, D.S., and Eger, J. E. (2001): Control of Mediterranean and Caribbean fruit flies (Diptera: Tephritidae) in commercial citrus groves in Florida using spinosad bait sprays. Florida Entomologist, 84: 672-678.

Costat, Software (1990): Microcomputer program analysis Version 4.2, CoHort Sofware, Berkeley, CA.

Dow Agrosciences. (2006): Supplemental Labeling, approved 06/05/06. GF-120 NF Naturalyte ${ }^{\circledR}$ Fruit Fly Bait. Indianapolis, IN.

Epsky, N. D.; Heath, R. R.; Sivinski, J. M.; Calkins, C. O.; Baranowski, R. M. and Fritz, A. H. (1993): Evaluation of protein bait formulations for the Caribbean fruit fly (Diptera:Tephritidae). Florida Entomologist, 76: 626-635.

Epsky, N. D., R. R. Heath, T. C. Holler, D. L. Harris, and T. Mullins. (1994): Corn steepwater as a protein bait for A. suspense (Diptera: Tephritidae). Environ. Entomol., 23: 827-831.

Epsky, N.D.; Hendrichs, J.; Katsoyannos, B. I.; Vasquez, L.A.;Ros, J.P.; Zumreoglu, A.; Pereira, R.; Bakri, A.; Seewooruthun,S.I. and Heath, R.R. (1999): Field evaluation of female-targeted trapping systems for Ceratitis capitata (Diptera : Tephritidae) in seven countries. J. Econ. Entomol., 92 : 156-164.
Epsky, N.D.; Kendra, P.E. and Schnell, E.Q. (2014): History and evelopment of food based attractants. Pheromones, Male Lures, and Trapping of Tephritid Fruit Flies, pp.75-118.

Hanafy, A. H.; Awad, A. I. and Abo-Sheasha, M. (2001): Field evaluation of different compounds for attracting adults of peach fruit fly Bactrocera zonata (Saunders) and Mediterranean fruit fly, Ceratitus capitata (Wied.) in guava orchards. J. Agric. Sci. Mansoura Univ., 26 (7): 4537-4546.

Heath, R. R.; Epsky, N.D.; Bloem, S. and Bloem, K. (1994): $\mathrm{pH}$ effect on the attractiveness of a corn hydrolysate to the Mediterranean fruit fly and several Anastrepha species (Diptera: Tephritidae). J. Econ. Entomol., 87: 1008-1013.

Hodson, A. C. (1948): Further studies of lures attractive to the apple maggot. J. Econ. Entomol., 41: 61-66.

Hu, X. P.; Prokopy, R. and Averill, A. (1999): Effects of pH on feeding responses in the apple maggot fly, Rhagoletis pomonella (Diptera: Tephritidae). J. Insect Physiol., 45:151-157.

[IAEA] International Atomic Energy Agency. 2003. Trapping guidelines for area-wide fruit fly programmes. IAEA, Vienna, Austria.

Khattak, S. U.; Afsar, K.; Hussain, N.; Khalil, S. K. and Alamzeb (1997): Annual population incidence of oriental fruit fly (Dacus dorsalis) Hendel in a fruit orchard at Peshawar, Pakistan Bangladesh J. Zoology, 18(2):131-138.

Michaud, J.P. (2003): Toxicity of fruit fly baits to beneficial insects in citrus. J. Insect Science 3: 1-9. Muehleisen, D., and Ostrom, M.. Managing Carrot.

Moreno, D. S. and Mangan, R. L. (2003): Bait matrix for novel toxicants for use in control of fruit flies (Diptera Tephritidae), pp. 333-362.In G. J. Hallman and C. Schwalbe [eds.], Invasive arthropods in agriculture: problems and solutions. Science Publishers, Inc., Enfield, NH. 
OEHHA (Office of Environ. Health Hazard Assessment). 2016. Health Questions and Answer for GF-120 NF Naturalyte ${ }^{\circ}$. California Environmental Protection Agency. Sacramento, alifornia, USA. 2pp.

Paiva, P. E. B. and Parra , J. R. P. (2013): Hydrogen ionic potential $(\mathrm{pH})$ of the attractant, trap density and control threshold for Ceratitis capitata (Diptera: Tephritidae) on Hamlin oranges in São Paulo central region, Brazil. Revista Brasileira de Fruticultura, 35: 464470.

Pelz-Stelinski, K. S.; Gut, L. J. and Isaacs, R. (2006): Behavioral responses of Rhagoletis cingulate (Diptera: Tephritidae) to GF-120 insecticidal bait enhanced with ammonium acetate. J. Econ. Entomol., 99: 1316-1320.

Piñero, J. C.; Mau, R.F.L and Vargas, R. I. (2011): A comparative assessment of the response of three fruit fly species (Diptera: Tephritidae) to a spinosad-based bait: Effect of ammonium acetate, female age, and protein hunger. Bull. Ent. Res., 101: 373-381.

Piñero, J. C.; Souder, S. K.; Smith, T. R.; Fox, A. J. and Vargas, R. I. (2015): Ammonium acetate enhances the attractiveness of a variety of protein-based baits to female Ceratitis capitata (Diptera: Tephritidae). J. Econ. Entomol., 108(2): 694-700.

Piñero, J. C.; Souder, S. T.; Smith, T. R. and Vargas, R. I. (2017):Attractionof Bactroceracucurbitae and Bactro cera dorsalis (Diptera: Tephritidae) to beer waste and other protein sources laced with ammonium acetate. Florida Entomologist 100(1):70-76.

Prokopy, R. J.; Miller, N. W. ; Piñero, J. C.; Barry, J. D.; Tran, L. C.; Oride, L. and Vargas, R. I. (2003): Effectiveness of GF-120 fruit fly bait spray applied to border area plants for control of melon flies. J. Econ. Entomol., 96:1485-1493.

Rendon, P.; Jeronimo, F.; Ibarra, J.; Acajabon, F., and Tween, G. (2000): Efectivad del product Success $0.02 \mathrm{CB}$ en el product Success $0.02 \mathrm{CB}$ en el control de moscas de las frutas y su efecto sobre abejas Apis mellifera L. USDA/APHIS/PPQ Report, 34pp

Rousse, P.; Duyck, P. F.; Quilici, S. and Ryckewaert, P. (2005): Adjustment of field cage methodology for testing food attractants for fruit flies (Diptera: Tephritidae). Ann. Entomol. Soc. Am., 98: 402-408.

Saafan, M. H. (2005): Field evaluation of some attractants for attracting the adults of Mediterranean fruit fly, Ceratitis capitata (Wiedemann) and peach fruit fly, Bactrocera zonata (Saunders) in citrus orchards. Egypt. J. Agric. Res., 83 (3): 11411156.

Steyskal, G.C. (1977): Pictorial key to species of the genus Anastrepha (Diptera: Tephritidae).Washington, D.C., Entomological Society of Washington, 35p.
Tan, K.H. and Nishida, R. (1998): Ecological significance of a male attractant in the defence and mating strategies of the fruit fly pest, Bactrocera papayae. Ent. Exp. appl., 89: 155-158.

Thomas, D. B. and Mangan, R. L. (2005.): Nontarget impact of spinosad GF-120 bait sprays for control of the Mexican fruit fly (Diptera: Tephritidae) in Texas. J. Econ. Entomol. , 98: 1950-1956.

Todd Shelly N. Epsky, E.B. Jang, J. Reyes-Flores, and R. Vargas, eds., (2014): Trapping and the detection, control, and regulation of tephritid fruit flies. Springer, Dordrecht, the Netherlands. DOI 10.1007/978-94-017-9193-9.

Vargas, R. I.; Leblanc, L.; Piñero, J.C. and Hoffman, K.M. (2014): Male annihilation, past, present, and future. p. 493-511 In T Shelly, N. Epsky, E.B. Jang, J. Reyes-Flores, and R. Vargas, eds., Trapping and the detection, control, and regulation of tephritid fruit flies. Springer, Dordrecht, The Netherlands.

Vargas, R.I.; Shelly, T.E.; Leblanc, L. and Piñero, J.C. (2010): Recent advances in methyl eugenol and cue-lure technologies for fruit fly detection, monitoring, and control. p. 575-596 In G. Litwack, ed., Vitamins and hormones, section: Pheromones, vol. 83.Academic Press, Burlington, VT.

Vargas, R. I.; Miller, N. W. and Prokopy, R. J. (2002): Attraction and feeding responses of Mediterranean fruit fly and a natural enemy to protein baits laced with two novel toxins, phloxine $\mathrm{B}$ and spinosad. Entomol. Exp. Appl., 102: 273-282

Vargas, R. I.; Mau, R.F.L.; Jang, E. B. ; Faust, R. M. and Wong, L.2008): The Hawaii Fruit Fly Area-Wide Pest Managemen Program, pp. 300 - 325.InO. Koul, G. W. Cuperus, and N. C. Elliott [eds.], Area wide IPM: theory to implementation. CABI Books, London, United Kingdom

White, I. M. and Elson-Harris, M. M. (1992): Fruit flies of economic significance: their identification and bionomics. CAB International, Wallingford. U.K., pp. 601

Yee, W. L. (2006): Feeding history effects on feeding responses of Rhagoletis indifferens (Dipt., Tephritidae) to GF-120 and Nulure. J. Applied Entomol., 130: 538-550.

Yee W. L. (2007): Attraction, feeding, and control of Rhagoletis pomonella (Diptera: Tephritidae) with GF-120 and added ammonia in Washington state. Fl. Entomol., 90: 665-673

Yee, w. L., and Chapman, p. S. (2005): Effects of GF-120 fruit fly bait concentrations on attraction, feeding, mortality, and control of Rhagoletis indifferens (Diptera: Tephritidae). J. Econ. Entomol. 98: 1654166.
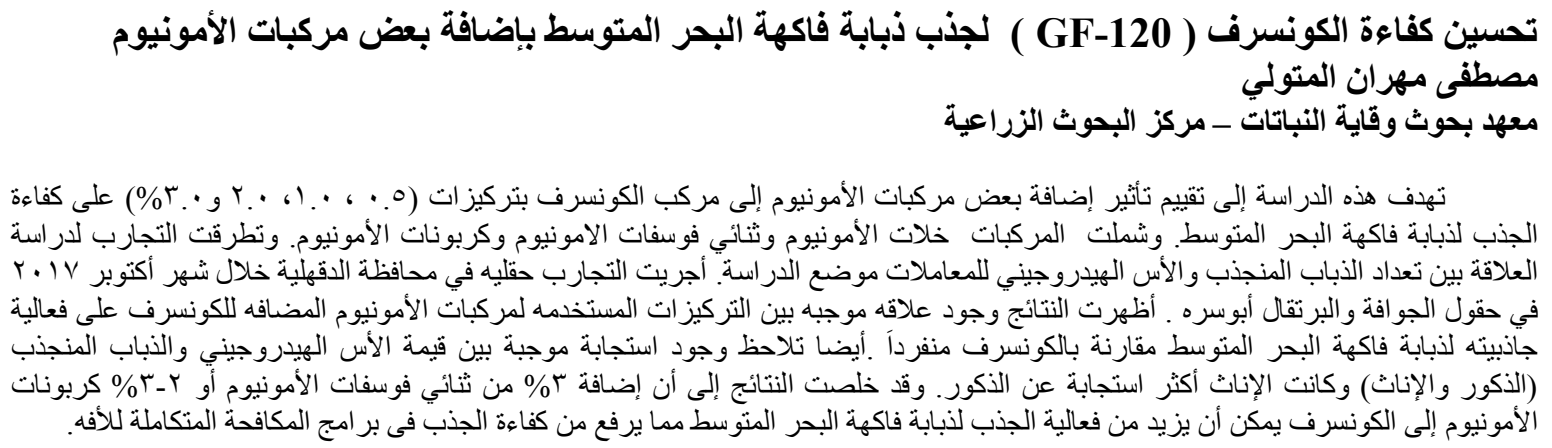